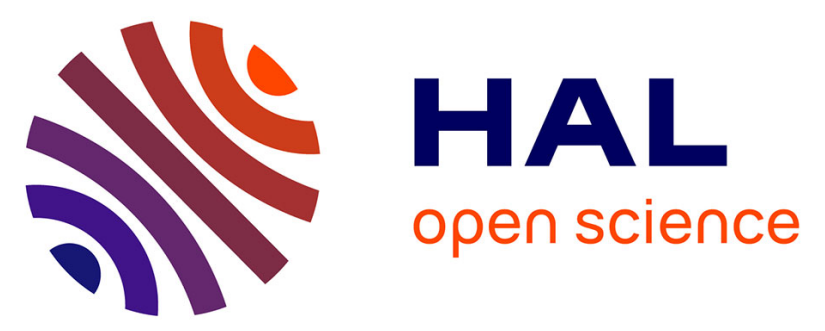

\title{
Miniaturized and Reconfigurable Notch Antennas Using a BST Thin Film Varactor
}

\author{
Viet Hung Nguyen, Caroline Borderon, Ratiba Benzerga, Christophe \\ Delaveaud, Ala Sharaiha, Hartmut Gundel
}

\section{- To cite this version:}

Viet Hung Nguyen, Caroline Borderon, Ratiba Benzerga, Christophe Delaveaud, Ala Sharaiha, et al.. Miniaturized and Reconfigurable Notch Antennas Using a BST Thin Film Varactor. International Symposium on Antennas and Propagation and USNC-URSI National Radio Science Meeting, Jul 2012, Chicago, United States. hal-00749723

\section{HAL Id: hal-00749723}

\section{https://hal.science/hal-00749723}

Submitted on 8 Nov 2012

HAL is a multi-disciplinary open access archive for the deposit and dissemination of scientific research documents, whether they are published or not. The documents may come from teaching and research institutions in France or abroad, or from public or private research centers.
L'archive ouverte pluridisciplinaire HAL, est destinée au dépôt et à la diffusion de documents scientifiques de niveau recherche, publiés ou non, émanant des établissements d'enseignement et de recherche français ou étrangers, des laboratoires publics ou privés. 


\title{
Miniaturized and Reconfigurable Notch Antennas Using a BST Thin Film Varactor
}

\author{
V. H. Nguyen ${ }^{1,2}$, C. Borderon ${ }^{1}$, R. Benzerga ${ }^{1}$, Ch. Delaveaud ${ }^{2}$, A. Sharaiha ${ }^{1}$, and H.W. Gundel ${ }^{1}$ \\ ${ }^{1}$ IETR, UMR-CNRS 6164, France \\ ${ }^{2}$ CEA-LETI, MINATEC, Grenoble, France \\ viet-hung.nguyen@univ-rennes1.fr
}

\begin{abstract}
Ferroelectric (FE) thin film varactor technology can be used for antenna miniaturization and reconfiguration. We present more particularly a quarter wavelength notch antenna with a Barium Strontium Titanate $\left(\mathrm{Ba}_{(1-\mathrm{x})} \mathrm{Sr}_{\mathrm{x}} \mathrm{TiO}_{3}, \mathrm{BST}\right)$ thin film in MIM geometry. Integration of the BST varactor yields a size reduction of approximately $56 \%$ with respect to the initial antenna size $\left(0.064 \times \lambda_{0}\right.$ without BST layer $)$ and the miniaturized antenna is tunable from $0.94 \mathrm{GHz}$ to $1.07 \mathrm{GHz}$.
\end{abstract}

\section{INTRODUCTION}

Wireless communication systems are becoming more and more complex and require small size components that have the ability to operate at multiple frequencies. Electrically small antennas that are frequency tunable allow the antenna to increase the operational bandwidth and, therefore, to cover multiple applications while fitting within a small package. This makes antenna miniaturization and reconfiguration a very attractive research topic.

Most often varactor diodes are studied for tuning planar antennas. A $3 \mathrm{GHz}$ - folded slot - antenna with varactors has been reported in [1] with a miniaturization of $30 \%$ and a tunablity of $5 \%$. A varactor tuned microstrip patch antenna has also been reported in [2]. The antenna, loaded with a varactor diode, has a center frequency of $2.13 \mathrm{GHz}$ and a tunablity of $10 \%$ under a DC bias voltage from 0 to $10 \mathrm{~V}$.

Ferroelectric (FE) Barium Strontium Titanate (BST) is one of the most extensively researched materials for RF and microwave applications, due to its high dielectric permittivity, large dielectric tunablity and relatively low dielectric losses [3]. In this paper, we report on a notch slot antenna with an integrated BST thin film varactor which is used for antenna miniaturization and reconfiguration. The size of the antenna is significantly reduced and the antenna frequency can be tuned.

\section{ANTENNA DESIGN}

\section{A. Design}

The notch antenna, which consists of a slot inside a metallic ground plane, is chosen as a design example. It is a complementary structure to the classical $\lambda / 4$ monopole, and has dual properties in terms of impedance and radiation behavior. When loaded by a capacitor, it presents a great advantage in terms of integration and miniaturization [4]. In this work, we discuss the effect of a BST thin film varactor loaded notch antenna.

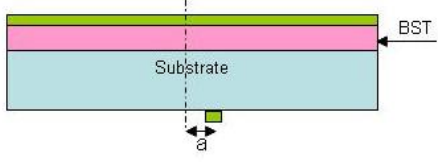

$\square$ : Metal

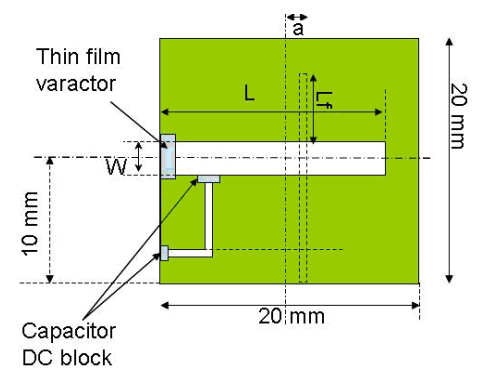

b) Top view
Figure 1: Schematic cross section view a) and top view b) of the BST thin film notch antenna

A schematic overall cross section view of the antenna, which is composed of fours layers, is shown in Figure 1a. It is based on the use of an alumina substrate serving as a support for the BST thin film deposition and the antenna metallization. The top view of the notch antenna geometry can be seen in Figure $1 \mathrm{~b}$, also indicating the position of the thin film varactor and two DC blocking capacitors. The slot of width $W$ and length $L$ is fed by a $50 \Omega$ microstrip line. In order to realize the impedance matching, the feed line is extended beyond the notch and hence constitutes a stub of length $L_{f}$ localized at the distance $a$ from the patch center line.

The details of the BST thin film varactor are shown in Figure 2. Two orthogonal metal electrodes, each $40 \mu \mathrm{m}$ large, separated by a $1 \mu \mathrm{m}$ thick BST layer, form an overlapping area of $1600 \mu \mathrm{m}^{2}$, thus constituting the tunable thin film capacitor.

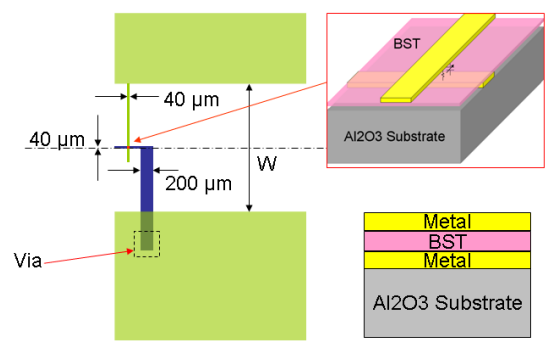

Figure 2: Details of the thin film varactor

In order to tune the dielectric permittivity of the BST film, a DC polarization voltage can be applied between the contact patch which is connected by a via to the capacitor's bottom electrode line, and the antenna main ground plate (containing the top electrode line). The latter is separated from the contact patch by two DC blocking capacitors (Fig. 1b). 


\section{B. Simulation}

The antenna has been simulated with the commercial software Ansys HFSS v13 for the optimized notch antenna dimensions: $W=2 \mathrm{~mm}, L=18 \mathrm{~mm}, L_{f}=7 \mathrm{~mm}$ and $a=1 \mathrm{~mm}$. The capacitance value of the two DC blocking capacitors is $180 \mathrm{pF}$, respectively. A dielectric permittivity of 95 and dielectric loss of $\tan \delta \approx 10^{-2}$ have been taken into account for the BST film and a change of the permittivity from 95 to 65 under the DC bias electric field has been supposed. The results of the return loss calculations of Figure 3 show a change of the antenna frequency from $0.94 \mathrm{GHz}$ to $1.07 \mathrm{GHz}$ or a tunablity of $13 \%$. Besides, the resonant frequency of the antenna without the BST layer is $2.2 \mathrm{GHz}$, and hence a size reduction of approximately $56 \%$ is achieved.

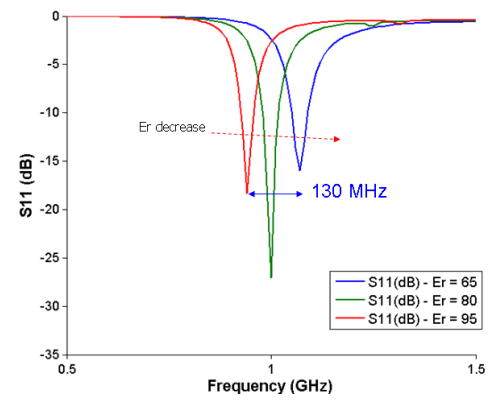

Figure 3: Return loss of the antenna vs dielectric permittivity of the BST thin film

\section{REALIZATION OF THE BST THIN FILM VARTACTOR}

The ferroelectric varactor structure in MIM geometry has been realized on the alumina substrate by successive deposition of the bottom electrode, the BST layer and the top electrode. The platinum electrodes of approximately $200 \mathrm{~nm}$ thickness were realized by magnetron sputtering.

Chemical solution deposition (C.S.D.) and spin-coating has been employed for the realization of the $\mathrm{Ba}_{(1-\mathrm{x})} \mathrm{Sr}_{\mathrm{x}} \mathrm{TiO}_{3}$ thin films [5]. The BST precursor solution is composed of barium and strontium acetates as well as titanium n-propoxide, mixed in appropriate portions, and uses an organic stabilizer. After deposition on the alumina substrate, a thermal heat treatment at $750^{\circ} \mathrm{C}$ allows crystallization into the ferroelectric perovskite structure. Multiple spin-coating has been used in order to obtain a final film thickness of approximately $1 \mu \mathrm{m}$. BST thin films with a homogenous surface and grain size are obtained, crystallization has been verified by X-Ray analysis and shows no parasitic phase.

Before depositing the top electrode, a via to the bottom electrode has been realized by wet chemical etching of the BST layer [6]. Deposition of the top electrode establishes the contact and thus completes the MIM varactor geometry.

The dielectric properties of the BST thin film are shown in Figure 4. An only slightly decreasing permittivity and loss $\tan \delta$ of approximately $1 \cdot 10^{-2}$ are obtained in the frequency range from $100 \mathrm{MHz}$ to $5 \mathrm{GHz}$. The reported experimental values also taking into account connection losses, the pure material dielectric loss are expected to be even smaller.

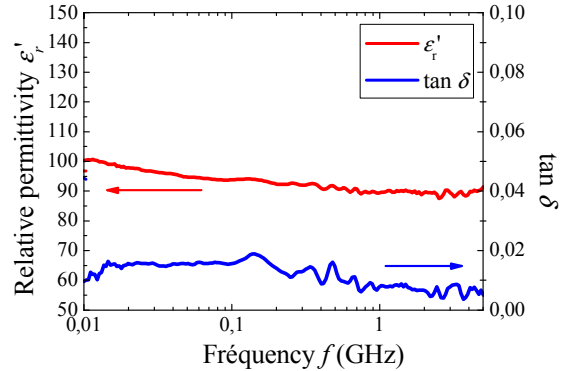

Figure 4: Dielectric permittivity and losses of the BST thin film as a function of frequency

The tunability of the BST thin film has been determined at a measuring frequency of $1 \mathrm{MHz}$ (Figure 5). The permittivity variation from 98 to 63 under a DC bias electric field of 400 $\mathrm{kV} / \mathrm{cm}$ corresponds to a tunablity of $35 \%$. Its evolution can be extrapolated from the experimentally observed overall behavior of the permittivity and corresponds to around $30 \%$ at $1 \mathrm{GHz}$.

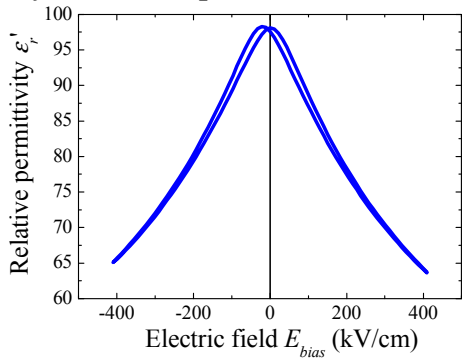

Figure 5: BST thin film tunability at $1 \mathrm{MHz}$

\section{CONCLUSION}

In this paper, a notch antenna design with an integrated BST thin film varactor has been studied. With the integrated varactor positioned at the open end of the antenna slot, significantly size reduction and its tuning capability has been obtained. An antenna miniaturization of $56 \%$ and an agility of $13 \%$ are reported by simulations. The experimental results will be presented and analyzed during the conference.

\section{REFERENCES}

[1] M. C. Scardelletti, G. E. Ponchak, J. L. Jordan, N. Jastram, and J. V. Mahaffey, "Tunable reduced size planar folded slot antenna utilizing varactor diodes," in 2010 IEEE Radio and Wireless Symposium (RWS), 2010, pp. 547-550.

[2] S. H. Al-Charchafchi and J. Kyriopoulos, "A varactor tuned microstrip patch antenna," in Antennas and Propagation, 1995., Ninth International Conference on Antennas and Propagation (Conf. Publ. No. 407), vol.1, 1995, pp. 278-281.

[3] N. K. Pervez, P. J. Hansen, and R. A. York, "High tunability barium strontium titanate thin films for rf circuit applications," Applied Physics Letters, vol. 85, no. 19, pp. 4451-4453, Nov. 2004.

[4] C. Lach, L. Rudant, C. Delaveaud, and A. Azoulay, "A new miniaturized antenna for ISM $433 \mathrm{MHz}$ frequency band," in 2010 Proceedings of the Fourth European Conference on Antennas and Propagation (EuCAP), 2010.

[5] C. Borderon, D. Averty, R. Seveno, H.W. Gundel, "Preparation and characterization of barium strontium titanate thin films by chemical solution deposition", Ferroelectrics 362 (2008), pp. 1-7.

[6] S. Pavy, S. Baron, C. Borderon, H.W. Gundel, "Wet chemical etching of BaSrTiO3 ferroelectric thin films", Proc. International Symposium on Intergated Fonctionalities" (ISIF 2011), July 31 - August 4, 2011, Cambridge, England. 